\title{
ENTRE LA DIVERSIÓN Y LA REVOLUCIÓN: EXPERIENCIAS CULTURALES DE LOS JÓVENES DE IZQUIERDA DURANTE LA UNIDAD POPULAR
}

\author{
YANNY SANTA CRUZ HENRÍQUEZ ${ }^{1}$
}

\begin{abstract}
RESUMEN
El presente artículo busca comprender las diversas experiencias culturales de los y las jóvenes de izquierda durante el periodo de la Unidad Popular a partir de tres ejes de análisis: los medios de comunicación, la producción y consumo musical, y un espacio más privado vinculado con la forma de comprender la sexualidad y el consumo de marihuana. A través de las fuentes analizadas, como revistas de época, prensa, documentos audiovisuales y entrevistas, problematizamos en torno a la construcción de esquemas o prototipos juveniles que conformaron una visión dual de la cultura; por un lado, un joven desatendido de su país y atraído por el hipismo, y por otro lado, un joven comprometido con los problemas políticos y sociales de Chile. Sin embargo, postulamos que la cultura juvenil de izquierda trabajada en esta investigación da cuenta más bien de experiencias culturales, definidas como las distintas propuestas y alternativas por las cuales transitaron los jóvenes, caracterizadas por el atractivo del movimiento hippie, la Nueva Canción Chilena y las nuevas y rupturistas maneras de vivir la sexualidad y el consumo de marihuana. Todos estos elementos configuraron una parte de la identidad juvenil revolucionaria, como muchos de ellos se nombraron en esta época.
\end{abstract}

PALABRAS ClaVes: CUlTURA JUVENIL, IZQUIERDA, NuEVA CANCIÓN CHILENA, REVISTAS JUVENILES.

${ }^{1}$ Estudiante del Doctorado en Historia, Universidad de Santiago de Chile (Becaria Conicyt), y magíster en Historia de la misma casa de estudios. Correo electrónico: yanny.santacruz@gmail.com. Trabajo realizado sobre la base de la tesis de Magíster denominada «Revolución Secundaria: La experiencia de los jóvenes secundarios de izquierda durante la Unidad Popular, Santiago 1970-1973», Universidad de Santiago de Chile, 2016. 


\title{
ENTRE A DIVERSÃO E A REVOLUÇÃO: EXPERIÊNCIAS CULTURAIS DOS JOVENS DE ESQUERDA DURANTE A UNIDADE POPULAR
}

\begin{abstract}
RESUMO
O presente artigo visa compreender as diversas experiências culturais dos e das jovens de esquerda durante o período da Unidade Popular a partir de três eixos de análise: a mídia, a produção e consumo musical e um espaço mais privado ligado à maneira de compreender a sexualidade e o consumo de maconha. A través das fontes analisadas, como revistas da época, imprensa, documentos audiovisuais e entrevistas, problematizamos em torno da construção de esquemas ou protótipos juvenis que formaram uma visão dupla da cultura, por um lado, um jovem que não se importa com seu país e é atraído pelo hipismo e, por outro lado, um jovem comprometido com os problemas políticos e sociais do Chile. No entanto, postulamos que a cultura juvenil de esquerda trabalhada nesta pesquisa, apresenta as experiências culturais, definidas como as diferentes propostas e alternativas pelas quais os jovens transitaram, caracterizada pela atratividade do movimento hippie, a Nueva Canción Chilena, e as novas e inovadoras formas de viver a sexualidade e o consumo de maconha. Todos estes elementos configuraram uma parte da identidade revolucionária da juventude, como muitos deles se chamavam nesta época.

PALAVRAS-CHAVE: CULTURA JUVENIL, ESQUERDA, NUEVA CANCIÓN CHILENA, REVISTAS JUVENIS.

\section{BETWEEN FUN AND REVOLUTION: CULTURAL EXPERIENCES OF LEFT-WING YOUNG PEOPLE DURING UNIDAd POPUlaR (POPUlaR UNITY)}

\begin{abstract}
The present article is aimed at understanding the diverse cultural experiences from leftwing male and female young people during Unidad Popular period, on the basis of three analysis axes: mass media, the production and consumption of music, and a more private sphere linked to their understanding of sexuality and marijuana consumption. Through the analyzed sources, including magazines, press, audiovisual documents and interviews from the time, we problematize towards the construction of youth schemes or prototypes made up a dual vision of culture: on the one hand, a young individual who is not interested in the country and attracted to the hippie movement; on the other hand, a young individual who is highly committed to the social and political problems of Chile. However, we state that the left-wing young culture worked in this research accounts for cultural experiences, defined as the diverse proposals and alternatives which young individuals gravitated towards, that are characterized by the attractiveness of the Hippie movement, the Nueva Canción Chilena movement, the new and groundbreaking ways of living sexuality and marijuana consumption. All these elements configured a part of the revolutionary youth identity, as they designated themselves.

KEYWORDS: YOUTH CULTURE, LEFT-WING, NUEVA CANCIÓN CHILENA, YOUTHORIENTED MAGAZINES.
\end{abstract}




\section{INTRODUCCIÓN}

Durante la Unidad Popular, Chile desarrolló dinámicas específicas en torno a su proceso político social, marcado por la vía institucional al socialismo alejado de la vía armada, tal como lo cantaba Víctor Jara en referencia a la Revolución cubana, «pero no somos guajiros, nuestra sierra es la elección» (Jara, 1971). Dicha vía tuvo como pilares económicos la reforma agraria, la nacionalización del cobre y la creación del Área de Propiedad Social, es decir, la estatización de los «sectores estratégicos» de la economía del país (Winn, 2013). Para llevar a cabo este proceso, fue fundamental contar con el apoyo y el accionar de diferentes actores sociales como trabajadores/as, profesionales, pobladores/as; en específico, los jóvenes fueron llamados a ser parte relevante de este proceso, a inmiscuirse en todos los ámbitos requeridos para fortalecer el proceso de la vía chilena al socialismo, tal como lo plantea Goicovic (2000): «Se les asignó a los jóvenes un rol estratégico, en cuanto actores y conductores, en el proceso movilizador que debía conducir al socialismo» (p. 115). Cada sujeto asumió y desplegó un papel específico en dicho contexto, pero, a su vez, fue gestando múltiples apropiaciones políticas y culturales al respecto. Como lo señala Peter Winn (2013): «La experiencia que un chileno tenía del proceso revolucionario variaba enormemente dependiendo de una multiplicidad de factores - clase, edad, sexo, política, trabajo y residencia, por nombrar unos pocos» (p. 43). Es en esta línea que cobra sentido comprender en específico las acciones desarrolladas por los jóvenes de izquierda en diálogo con este «deber ser», en uno de los procesos más álgidos de la historia de Chile. Además, debemos considerar que los cambios, experiencias y apropiaciones no se restringieron solo a la estructura económica y política, sino también a desplegar una nueva cultura, el llamado fue a crear un «hombre nuevo» en el Chile del siglo XX (Álvarez, 2014). Una nueva cultura fundamentada en la colaboración y participación social, conscientes de las problemáticas que atravesaba el país y dispuestos a cambiarlas.

Ahora bien, analizando en específico la vinculación de la juventud y los elementos culturales, el Chile del periodo de la Unidad Popular se insertó en una realidad global, que tuvo como antecedente y/o influencia en nuestro país la Revolución cubana, la guerra de Vietnam y los movimientos juveniles que irrumpían en casi todo el mundo, las protestas antimilitaristas y por los derechos civiles en EE.UU., las luchas universitarias en busca de una mayor democratización en Francia, Argentina y México, entre otros, y la ascensión de una contracultura juvenil que se enfrentaba a los viejos cánones establecidos 
por sus ascendientes, instaurando una verdadera «era de la juventud» (Manzano, 2017), etapa que se ha caracterizado por contener elementos culturales transnacionales que se fueron entretejiendo con otras identidades (Zolov, 2002). Esta contracultura se manifestó principalmente en las expresiones musicales, las manifestaciones artísticas y las concepciones respecto del sexo y los roles de género, ámbitos en los que centraremos nuestra investigación.

Por lo tanto, la pregunta que guía este trabajo es establecer ¿cómo se desarrolló la experiencia cultural de los jóvenes de izquierda durante la Unidad Popular? ${ }^{2}$ Entendiendo a la experiencia como un estar siendo ${ }^{3}$, el que parte de lo que el sujeto ha vivido y construido, no desprendiéndose de elementos materiales, como las condiciones económicas y sociales, sino entendiendo que estas, en conjunto con otras realidades, se configuran en los diferentes tipos de acción y discurso de los sujetos juveniles, «porque la experiencia surge espontáneamente en el interior del ser social, pero no surge sin pensamiento; surge porque los hombres y mujeres (y no sólo los filósofos) son racionales y piensan acerca de lo que les ocurre a ellos y a su mundo» (Thompson, 1981: 19).

Como la experiencia constituye parte primordial de este trabajo, los testimonios ${ }^{4}$ son herramientas trascendentales para comprender las diversas

${ }^{2}$ Para ahondar en las experiencias y participación política de los jóvenes, ver: Jorge Rojas Flores (2009). Los estudiantes secundarios durante la Unidad Popular, 19701973. Historia, II(42); Santa Cruz, Y. (2019). Las y los pingüinos en la Unidad Popular. La vida política de los estudiantes secundarios de izquierda en Santiago. En G. D. Germinal, Se levanta el clamor popular. Experiencias del pueblo organizado durante el gobierno de los mil días 1970-1973 (pp. 159-194). Concepción: Sartaña.

${ }^{3}$ El concepto de experiencia aplicado al periodo de la Unidad Popular también ha sido trabajado en los textos: Winn, P. (2004). Tejedores de la Revolución. Los trabajadores de Yarur y la vía chilena al socialismo. Santiago de Chile: LOM Ediciones. Cury, M. (2018). El protagonismo popular chileno. experiencias de clase y movimientos sociales en la construcción del socialismo (1964-1973). Santiago de Chile: LOM Ediciones.

${ }^{4}$ Esta investigación utilizó como fuente de información la Colección del Archivo de Villa Grimaldi de la Corporación Parque por la Paz Villa Grimaldi. La autora agradece el acceso a los registros de la Colección. Todos los resultados del estudio son de responsabilidad de la autora y en nada comprometen a dicha institución. 
acciones y lecturas de los otrora jóvenes, considerando que «los relatos de vida permiten reconstituir la dimensión microsocial, podríamos decir "molecular", de las acciones colectivas» (Gaudichaud, 2013: 75). Igualmente, se analizó material musical, audiovisual y revistas de época, ya que las imágenes, letras e interpretaciones de este tipo de fuentes otorgan una mirada y comprensión más profunda al desarrollo cultural de los jóvenes, y para el caso específico de este estudio, jóvenes vinculados a partidos políticos de izquierda, que representan solo una parte de los múltiples discursos y acciones de estos mismos.

A partir de lo anterior, establecemos que, si bien los jóvenes de izquierda fueron partícipes primordiales del proceso llevado a cabo por la Unidad Popular, en torno a diferentes espacios de politización como los trabajos voluntarios, las marchas, protestas y las militancias políticas, también fueron gestando elementos culturales específicos (muchos de ellos disímiles), desplegando prácticas propias como jóvenes. Es decir, en un contexto donde se gestaron dos prototipos juveniles, uno más ligado al deber ser del joven de izquierda, es decir, la formación de una cultura musical, identitaria e incluso gráfica que se denotaba al joven comprometido con la causa revolucionaria, y otra que se mostraba un prototipo implantado, gringo, desde el movimiento hippie. Así, a pesar del modelo de juventud despreocupado y apolítico promovido por los medios de comunicación trabajados en esta investigación, como el programa Música Libre o la revista Ritmo, inspirados en patrones culturales norteamericanos, o desde la política cultural adultocéntrica de la izquierda, es decir, la construcción de una cultura al compás de la revolución ${ }^{5}$, la experiencia cultural de los jóvenes de izquierda fue complejizada $y$, si bien estuvo vinculada al compromiso político, también buscaron canales de diversas expresiones. De este modo, a través de los tres ejes exploratorios estudiados, proponemos que los jóvenes de izquierda rompieron la categorización binaria de la cultura juvenil al transitar entre variadas alternativas del espectro identitario, nutriéndose de las muchas opciones que presentaba el mundo en

${ }^{5}$ El gobierno de Salvador Allende influyó hondamente en una «construcción cultural acerca de la juventud referida a un imaginario latinoamericanista y a un "deber ser" juvenil». En uno de sus discursos señalaría: «Qué puede significar más que estar junto a la juventud, y sentir cómo ella late y presurosamente, con una clara conciencia revolucionaria y antiimperialista» (Moraga Valle, F., (2006). Ser joven y no ser revolucionario. La juventud y el movimiento estudiantil durante la Unidad Popular. En F. Zapata, Frágiles suturas. Chile a treinta años del gobierno de Salvador Allende (pp. 365-411). México, D. F.: El Colegio de México, p. 369. 
efervescencia. En este sentido, concordamos con Francisco Ramírez cuando señala que «los jóvenes no construyen una "cultura juvenil", sino que son capaces de tomar sus decisiones y elecciones de las prácticas sociales, que los distinguirán como una "cultura juvenil"» (Ramírez, 2008: 89).

Considerando las expresiones por las cuales se han analizado los aspectos de las culturas juveniles de la década de los sesenta (Barr-Melej, 2017; Manzano, 2017; Zolov, 2002), y respondiendo las inquietudes específicas de esta investigación, iniciamos el artículo con un apartado sobre los discursos de los principales medios de comunicación, tales como las revistas Ritmo, Onda y Ramona, medios representativos del sector juvenil que se estudiará, y el programa de televisión Música Libre, en torno al deber ser del joven. Posteriormente revisaremos los ritmos musicales de la época, como la Nueva Canción Chilena y la Nueva Ola, y la apropiación de estos ámbitos por parte de los jóvenes. Por último, nos adentraremos en un ámbito más íntimo de los jóvenes, preguntándonos sobre los debates y percepciones del sexo y las drogas entre los adolescentes.

\section{LOS MEDIOS DE COMUNICACIÓN Y LA JUVENTUD}

Desde una mirada más clásica y conservadora de la sociedad, se generó una idea de juventud con demarcaciones claras y definidas, sujetos preocupados solo de la diversión y de «pasarlo chancho», «groso» ${ }^{6}$. Los bailes, las conversaciones y las reuniones expresaron el deseo común de disfrutar de la juventud como estado pasajero de la vida, interpretando sus experiencias como una etapa sin mayores aflicciones o problemas. Lolos y lolas, preocupados(as) por su apariencia, de sus amoríos, de sus salidas cotidianas con las amigas/os o pololos/as, fueron forjando «ideas» y estereotipos basados en la construcción de jóvenes incapaces de tomar decisiones políticas importantes, de posicionarse frente a temas nacionales, a conflictos políticos, a pensar un país diferente. Así, a través de los medios de comunicación, tales como la revista Ritmo y el programa de televisión Música Libre, se masificó una idea de juventud asociada a «problemas típicos» de su edad, livianos y superficiales.

${ }^{6}$ Términos acuñados en la época por los y las jóvenes, utilizado como sinónimo de espectacular, genial o bueno. 
La revista Ritmo nació en septiembre de 1965 y se mantuvo hasta 1975. Su público objetivo fueron los jóvenes entre 12 a 17 años (alcanzando una audiencia principalmente femenina). Las múltiples imágenes en las portadas daban cuenta de una juventud llena de alegría, carisma y diversión, mostrando una forma de ser joven a través de elementos estructurantes. La «jovialidad», término usado de manera idealizada, adquirió cuerpo en los diferentes reportajes y fotografías publicados, que negaban los elementos complejos de los procesos vividos por las y los jóvenes durante la Unidad Popular ${ }^{7}$. En el despliegue de varias de sus secciones pretendió dar cuenta de una juventud despolitizada desligada del contexto social que se vivía en el país. Así lo explica Silvia Lamadrid (2014) en relación con la juventud lectora de Ritmo:

(...) su potencial subversivo y creador era neutralizado para integrarse en la obediencia a un orden social presentado como integrado, donde se subraya la realización personal dentro de los límites de la interioridad y el desarrollo de valores afectivos, en un mundo privado separado de la realidad exterior. (p. 375)

Para la autora, que investigó en profundidad este medio escrito, la revista Ritmo fue importante en generar discursos y «reglamentos» difundidos en sus diferentes secciones. En estas se presentaban dos elementos fundamentales: el primero de ellos tiene relación con la valoración en torno al mérito. Esto quiere decir, la puesta en valor del esfuerzo individual, anulando las capacidades críticas. El segundo se refiere al rol de la mujer, realzando su subordinación a la sociedad y a la familia. En este sentido, es importante destacar que desde fines de los sesenta y principios de los setenta comenzó una segunda oleada de la corriente feminista, que buscó generar un quiebre en torno a los principales perfiles femeninos: la dueña de casa, la esposa, la madre dedicada a los hijos, en fin, la supeditación de la mujer frente al hombre. Este elemento, conjugado con la creación y distribución de la pastilla anticonceptiva, fueron definiendo visiones contrapuestas en torno al rol social de la mujer. De esta manera, las cartas, mensajes y reportajes de la revista forjaron un lenguaje en común, enfocado en la preparación de la joven mujer para el matrimonio (Lamadrid, 2014).

${ }^{7}$ Revista perteneciente a la Editorial Lord Cochrane, vinculada al grupo Edwards, con una clara tendencia conservadora y de derecha. 
En 1970 inició sus transmisiones, por la señal de Televisión Nacional de Chile (TVN), el programa televisivo Música Libre $(M L)$, emitido de lunes a viernes a las 18 horas. Durante su período al aire se abocó a propagar un tipo específico de juventud, separados de una sociedad tensionada por los ideales políticos. Diariamente, lolitas y lolitos bailaban y realizaban representaciones musicales al ritmo del rock and roll y la Nueva Ola Chilena (Salas, 2003). Mujeres que se vestían con minifaldas, poleras cortas y apretadas movían sus cabellos largos y lisos en la pantalla, mientras que los hombres, de pie en el escenario, vestidos con pantalones blancos de corte «elefante» y con poleras sin mangas, realizaban movimientos de «baile libre», que daban cuenta de la distención y tranquilidad que se vivía entre la juventud ${ }^{8}$. Las temáticas no variaban y se construían siempre a partir de canciones románticas o de diversión. Incluso se bailaron canciones en inglés, en un contexto en que toda la cultura producida desde Estados Unidos era entendida por sectores de izquierda como un influjo imperialista y capitalista, es decir, como una forma de enajenación social, símbolo material de la dominación y la hegemonía yanqui en el mundo (Manzano, 2017). Mientras que unos gritaban «Gringo go home», otros (o los mismos) probablemente cantaban «There's a lady who's sure, all that glitters is gold, And she's buying a stairway to heaven, And when she gets there» (Led Zeppelin, 1971). Al verlo, pareciera que ninguno de los conflictos y tensiones nombrados anteriormente existiese. Nada podría indicar que algo estaba ocurriendo afuera, lejos de la pantalla.

Así, $M L$ fue irradiando una idea de juventud completamente desatendida de su realidad, un lolerío absorbido por estos líderes musicales y las melodías que inundaban las pantallas chilenas. Prototipos juveniles que representaban la lejanía entre esa jovialidad esperada y el compromiso político. Sin embargo, y a pesar de que los discursos oficialistas y el adultocentrismo partidista de izquierda querían enterrar esos prototipos y acciones, la revista Ramona, perteneciente a las Juventudes Comunista, mantuvo siempre reportajes referidos a este programa. Un ejemplo de esto fue la entrevista que le realizaron a un participante de este grupo de bailarines que declaraba en la revista: «(...) es como estar en fiestas todos los días, y además te pagan» (Ramona, 1971: 11).

${ }^{8}$ Es necesario mencionar que, aunque la televisión no tenía la misma masificación que en la actualidad, el gobierno de Salvador Allende, a través de la Industria de Radio y Televisión (IRT), se propuso desarrollar productos electrónicos a bajo costo a través de los televisores ANTU. 
¡Un festín diario! De alguna manera, el baile y su masificación daban cuenta de la necesidad de una construcción juvenil alegre y divertida, pero que al plasmarse en Ramona podemos nombrarla también como una juventud «políticamente comprometida». Ahora bien, la disputa sobre el papel de la juventud siempre ha sido disímil, así se manifiestan en las palabras de un entrevistado del documental Descomedidos y Chascones, realizado por Carlos Flores (1973), quien declaró: «La juventud no se tiene que preocupar tanto de política, sino de su felicidad». Este documental, que extrema e ironiza sobre las posiciones y roles, establece tres categorías bastantes delimitadas, una juventud de izquierda, otra de derecha y otra «ni ahí»» ${ }^{9}$ con el país, pero veremos que la vivencia cultural es mucho más compleja que estas tres divisiones.

Música Libre y Ritmo fueron medios masivos que dialogaron con esta juventud comprometida. En palabras de María Luisa Ortíz (Entrevista, 2016), quien en esos años militaba en el Partido Comunista, «éramos adolescentes también, mirábamos Música Libre igual, y nos gustaban los "minos" de Música Libre, no era una cosa excesivamente cuadrada, al menos yo no la viví así, quizás después en dictadura». Algo similar describe Jorge Rojas Flores (2009), cuando, producto de la emisión de un capítulo de $M L$, fue suspendida una reunión del MIR. De esta manera, las reuniones, concentraciones y encuentros convocaron diferentes modelos juveniles.

Sumado a esto, la idea y cultura juvenil que se quería imponer en los medios de comunicación masiva se encontraba directamente ligada a los modelos provenientes de Estados Unidos. El hipismo, como corriente de la cultura juvenil, pasó a tener un rol fundamental como expresión de los jóvenes chilenos, principalmente los de clase alta. Vaciando este movimiento de sus propuestas más interesantes, de la fuerte y aguda crítica social en la que se construyó, los medios de comunicación buscaron utilizarlo para forjar una juventud superficial. Esto significó que, en términos simples, el hipismo no solo constituyó modos de vestir diferentes, como el uso de jeans, poleras teñidas de múltiples colores, cintillos en la cabeza o el pelo suelto, sino también implicó la utilización de drogas como la marihuana y el LSD. A pesar de lo anterior, la derecha y los grupos más conservadores también promovieron una represión en torno a la liberación e imagen de estos «hippies criollos» (Barr-Melej, 2017). Estas imágenes y vestimentas, sobre todo los jeans, calaron profundamente en

\footnotetext{
${ }^{9}$ Término acuñado para mencionar el desinterés o despreocupación por algo o alguien.
} 
los jóvenes de izquierda, tal como lo menciona Lelia Pérez (Testimonio $\mathrm{N}^{\circ} 2$, 2006), exmilitante del Movimiento de Izquierda Revolucionaria (MIR), quien recuerda: «(...) el fenómeno del hipismo me atraía profundamente. El tener jeans era una cosa que me atraía muchísimo, y nunca logré tener uno». Con esta frase, y la experiencia de esta militante del MIR, la idea de una cultura juvenil maniquea, superficial y vacía comienza a complejizarse y entrelazarse.

La irrupción de este hipismo, sin contenido social y cultural, fue entendida por los sectores de izquierda como una importación más, dentro de las múltiples intervenciones económicas y políticas de los Estados Unidos. Así lo muestra el texto «Viaje por la juventud», cuando caracteriza a los «lolitos tuercas en las Vizcachas», refiriéndose a los encuentros que se realizaban los domingos en el autódromo de dicho lugar:

El espectáculo es multicolor y floripondioso. Se lleva mucho el «Vizcachas Style», último alarido de la moda: pantalones «guargüero de pollo»; chalecos multicolores anudados a la cintura; blusa con motivos Peace; casaca de mezclilla Made in USA o parka «escandinava de las legítimas...». (Abarca y Forch, 1972: 36)

Este relato muestra la ironía con la que era vista la juventud que miraba la cultura yankie, buscaba así desprender estos cánones y «centrar» una juventud en su papel fundamental, sobre todo basado en la valoración del trabajo y de la construcción de una nueva sociedad. En este sentido, la promoción a los trabajos voluntarios de los y las jóvenes, como un deber ser, se plasmó en los medios de comunicación, específicamente en la revista Ramona y Onda ${ }^{10}$. Es en esta última donde se relatan los trabajos voluntarios realizados en la comunidad de Cabildo: «En la tarde, los que trabajaron en la mañana estarán libres y otros ocuparán su lugar. En la noche se reúnen a cantar, claro que no con tanto entusiasmo como los primeros días. El trabajo los ha vuelto muy responsables para sus horas de sueño» (Onda, 1972: 63). A través de sus números, podemos comprender la relevancia de los trabajos voluntarios para esta idea de juventud (Álvarez, 2014), que muchas veces buscó alejar los cánones importados, o incluso, de las propias decisiones de los jóvenes. Esto se encuentra estrechamente ligado al propósito editorial de la revista, que buscó ser una alternativa frente a Ritmo, donde se pudieran tratar temáticas ligadas a

\footnotetext{
${ }^{10}$ Revista dirigida a la juventud de la editorial Quimantú, nacionalizada por el gobierno de Salvador Allende.
} 
la juventud, pero orientadas al compromiso político-social del gobierno. Pero los jóvenes hicieron de su vivencia algo más poroso, en palabras de Vilma Araya (Entrevista, 2016), militante de las Juventudes Comunistas: «Me fascinaba toda esta onda, entre hippie, entre de izquierda, entre peña, entre canturreo, y participar mucho en los trabajos de toda esta onda ${ }^{11}$. Para Vilma, en particular, pero también para toda una generación, la cultura juvenil fue permeable a diversas manifestaciones.

\section{Al RITMO de LA REVOLUCión}

De forma paralela al desarrollo de la música y moda ligada a la cultura gringa en nuestro país, surgió una nueva corriente musical en la década de los sesenta, que se fue conformando como la banda sonora de los distintos conflictos durante el periodo de la Unidad Popular; nos referimos a la Nueva Canción Chilena (NCCH). Grupos como Quilapayún, Inti Illimani o el propio Víctor Jara fueron algunos de los exponentes más relevantes de esta «nueva» forma de entender y hacer música en Chile. Si bien sus antecedentes pueden encontrarse en la década de 1950 con las obras de Violeta Parra, Margot Loyola y los grupos folklóricos Cucumén y Millaray, la NCCH alcanzó su mayor potencial durante el gobierno de Salvador Allende, al reunir en una propuesta común, influencias latinoamericanas, aspiraciones revolucionarias y un marcado compromiso con el pueblo pobre. Tal como lo menciona J. Patrice McSherry (2017): «El movimiento de la nueva canción era parte orgánica de amplios movimientos populares de la época y desempeñó un rol clave en el movimiento por la democratización "desde abajo" para transformar el Estado y la sociedad en Chile» (p. 255).

El canto en español se resistió a desaparecer, ligándose a los diferentes proceso políticos y sociales que se vivían en el país. Así, la NCCH tuvo un rol fundamental durante las tensiones sociales que debió atravesar el gobierno de la UP, participando en la ardua tarea de generar una mayor concientización y compromiso social. En este sentido, la Discoteca del Cantar Popular (DICAP), sello discográfico perteneciente a las Juventudes Comunistas ${ }^{12}$, juega un papel

\footnotetext{
${ }^{11}$ Refiriéndose a los trabajos voluntarios.

${ }^{12}$ Antes sello Jota Jota.
} 
trascendental en la masificación y puesta en valor de los y las artistas anteriormente nombradas, y que desarrolló una apuesta cultural basada en letras que relatan al campesino, trabajador, minero y, por supuesto, el «socialismo a la chilena».

Cuando la Canción del Poder Popular mencionaba «porque esta vez no se trata de cambiar a un presidente, será el pueblo que construya un Chile bien diferente» (Inti Illimani, 1970), refería a que la revolución, el cambio y el compromiso formaban parte de la música y de la cultura de la época. Esta concepción fue compartida igualmente por el gobierno de Salvador Allende quien, según Marisol García (2013), llegó a declarar, en abril de 1970, en periodo de campaña presidencial, que «no hay revolución sin canciones. Jamás hubo tantos folcloristas y de tanta calidad. Con nosotros están los más y mejores» (p. 125).

Pero, a pesar de la importancia que fue asumida en torno al desarrollo de esta música comprometida, dicha autora es categórica en mencionar que este movimiento musical no alcanzó los niveles de popularidad de la Nueva Ola, las cumbias o la balada romántica (García, 2013). Sin embargo, entre los jóvenes de izquierda, cantar y escuchar algunas de estas canciones fue parte fundamental de quehacer político diario. María Eugenia Letelier (Entrevista, 2015), quien fue militante del MIR, relata cómo la participación en el Centro de Alumnos de su colegio le permitió realizar acciones de apropiación de espacios, mediante la disposición de parlantes para poner música en los recreos: «Pedimos permiso pa' poner música de protestas... entonces poníamos Quilapayún, Intilllimani, no sé... Ángel Parra, Violeta Parra. Entonces, esa era una conquista. Una conquista de espacio yo te diría. Tomarse un espacio de distención, como es el recreo en el liceo y poder concientizar a través de la música, fue uno de los elementos fundamentales para comprender el diario vivir, el estar siendo, en este caso específico, de los secundarios. Esta dinámica fue definiendo una íntima relación entre los proyectos políticos con la práctica en los diferentes espacios cotidianos.

La lucha por la democratización de los espacios y la apropiación subjetiva de la revolución (Álvarez, 2014) que estaba en marcha se experimentó a través de la música. Los diferentes cantautores afines a la $\mathrm{NCCH}$ fueron estableciendo lazos cada vez más importantes con el pueblo chileno, al presentarse como portavoces de sus causas más necesarias. De esta manera, las diferentes concentraciones, celebraciones o actos del gobierno contaron su actuación. Por ejemplo, en la celebración del Día Nacional del Trabajo 
Voluntario de 1972 participaron artistas musicales como Quilapayún, Ángel e Isabel Parra. Todos ellos, a través del tejido de las letras, pusieron en valor la identidad del pueblo chileno, del campesino, trabajador y minero, forjando canciones de protestas en torno a las injusticias ocurridas en la historia de Chile y América. Ejemplo de esto es la canción de Quilapayún, A la mina no voy (1969), que relata la desazón de un «negro» obligado a trabajar:

Cuando vuelvo de la mina

cansado del carretón

encuentro a mi negra triste

abandonada de Dios

y a mis negritos con hambre

¿por qué esto, pregunto yo?

Un hito destacado de este desarrollo musical fue el Festival de la Nueva Canción Chilena en 1969, organizado por el locutor radial Ricardo García y la Pontificia Universidad Católica de Chile. Este encuentro se realizaría anualmente, suscitando profundas críticas a dicha casa de estudio, por haber dejado «entrar el marxismo a la Universidad» (Salas, 2003: 68), dando cuenta del resquemor que se gestaba en torno al «avance» y desarrollo de esta corriente musical. Porque las letras y melodías avanzaban al compás de los sucesos, de la revolución.

La estrecha vinculación entre el tipo de música escuchada y la participación política parece fundirse entre diferentes intereses, debido a que, si bien la NCCH fue fundamental en el diálogo con el elemento político, esto no fue determinante o excluyente para que algunos jóvenes exploraran «otras culturas», otras maneras de «estar siendo», logrando transitar entre un «prototipo superficial» a otro comprometido y coherente con el proyecto revolucionario. Sin embargo, sería sesgado otorgarle una especie rol totalizante en la cultura juvenil a la $\mathrm{NCCH}$, pues el consumo y circulación del rock anglo también estuvieron presentes en el contexto de la revolución a la chilena y, por qué no, en el escenario político de los jóvenes. Pero el uso del inglés no solo significaba hablar el idioma del imperio, para las líneas más dogmáticas de la izquierda chilena, sino que representaba además la manera en que los jóvenes, al cantar una canción, no dijeran nada. Cantar en inglés fue fuertemente 
criticado, es que ¿quién iba a entenderlos? El pueblo no. De este modo, se configuró un rechazo por parte de la izquierda por cantar y escuchar canciones en un idioma que se constituyó como símbolo del capitalismo. De acuerdo con Fabio Salas (2003), «el rockero chileno era entonces rápidamente catalogado como "colonizado" o "alienado"» (p. 35).

Así, el canto en español se consideró como una resistencia en torno a la hegemonía cultural que quería imponer Estados Unidos (McSherry, 2017). A pesar de lo anterior, esta música caló profundamente en la juventud; un ejemplo de ellos fue lo que se denominó «el Woodstock chileno»: el Festival de Piedra Roja, encuentro musical realizado el mes de octubre de 1970 y que tuvo como propósito congregar a músicos y asistentes amantes del rock, imitando, de alguna manera, la cultura gringa. Y, aunque este festival fuese fuertemente criticado por todos los sectores de la sociedad chilena, su inesperada masividad materializa un interés musical no solo en los «hippies de Providencia», sino también de una vasta juventud (Barr-Melej, 2009). Por lo tanto, los jóvenes de izquierda, si bien se relacionaron íntimamente en ambientes, fiestas y malones, donde la NCCH fue central, también escucharon y disfrutaron de las canciones en inglés. Fueron capaces de moverse dentro de múltiples «ofertas culturales», que, en el caso de la música, no derivaron en la pérdida de interés por continuar con sus proyectos e ideas políticos. En otras palabras, si bien escuchaban música comprometida o bailaban al compás de Inti Illimani, reforzando su compromiso revolucionario, también leyeron la revista Ritmo o cantaron algunas de las canciones de Pink Floyd ${ }^{13}$.

Un aspecto fundamental relacionado con la expresión y consumo musical fue la gráfica asociada a esta, un lenguaje específico que caracterizó la estética de los discos de la NCCH. En este ámbito, se destaca el trabajo realizado por la oficina de diseño gráfico de los hermanos Larrea, quienes fueron centrales en esta creación, así como también en desarrollar una gráfica identitaria de la década de los sesenta en nuestro país, con portadas de discos y películas, pero también para crear afiches promocionando medidas del gobierno. Cabe mencionar que esta estética se vinculó directamente con el

${ }^{13}$ Quizás una materialización y experiencia de esta búsqueda cultural fue el propio Víctor Jara, quien invitó a los Blops, heredera de sonidos eléctricos y rockeros, a ser la banda de las canciones El derecho de vivir en paz y Abre tu ventana. García, M. (2013). Canción valiente. 1960-1989. Tres décadas de canto social y político en Chile. Santiago de Chile: Ediciones B. 
desarrollo del muralismo, materializado fundamentalmente en las Brigadas Ramona Parra y Elmo Catalán ${ }^{14}$ (Castillo, 2004). De esta manera, se configuró una propuesta artístico-política, que permeaba al ámbito musical, cuyo influjo provenía de las vallas cubanas (respecto a la llegada de un mensaje concientizador a un público masivo), el realismo socialista (estilo artístico que buscó representar las luchas revolucionarias del proletariado y el campesinado), el muralismo mexicano (en cuanto arte popular comprometido y colectivo), el pop-art (por medio del uso de colores brillantes, flores, aves y otros recursos gráficos provenientes del mundo hippie y de la sicodelia) y los grabados militantes de José Venturelli y Pedro Lobos (Grandón, 2010).

Observamos que los colores, trazos y brochas también se entremezclan con otros patrones internacionales, característicos de los procesos de contracultura juvenil de la década de los sesenta; basta con observar el video de The Beatles y la portada creada por la oficina de los hermanos Larrea para el cantautor Ángel Parra o una portada la revista Onda con el cantante de balada romántica Leonardo Favio, como se muestra a continuación. Las tres imágenes, de diferentes corrientes musicales, tienen un tratamiento gráfico relativamente parecido, lo que demuestra la interconexión, y no la disociación, entre la izquierda y la cultura internacional o hippie.

14 Brigadas muralistas vinculadas al Partido Comunista y Partido Socialista, respectivamente. En paralelo existió el Comando Rolando Matus, grupo de choque de la derecha que buscó hacer frente a las brigadas anteriormente nombradas. 

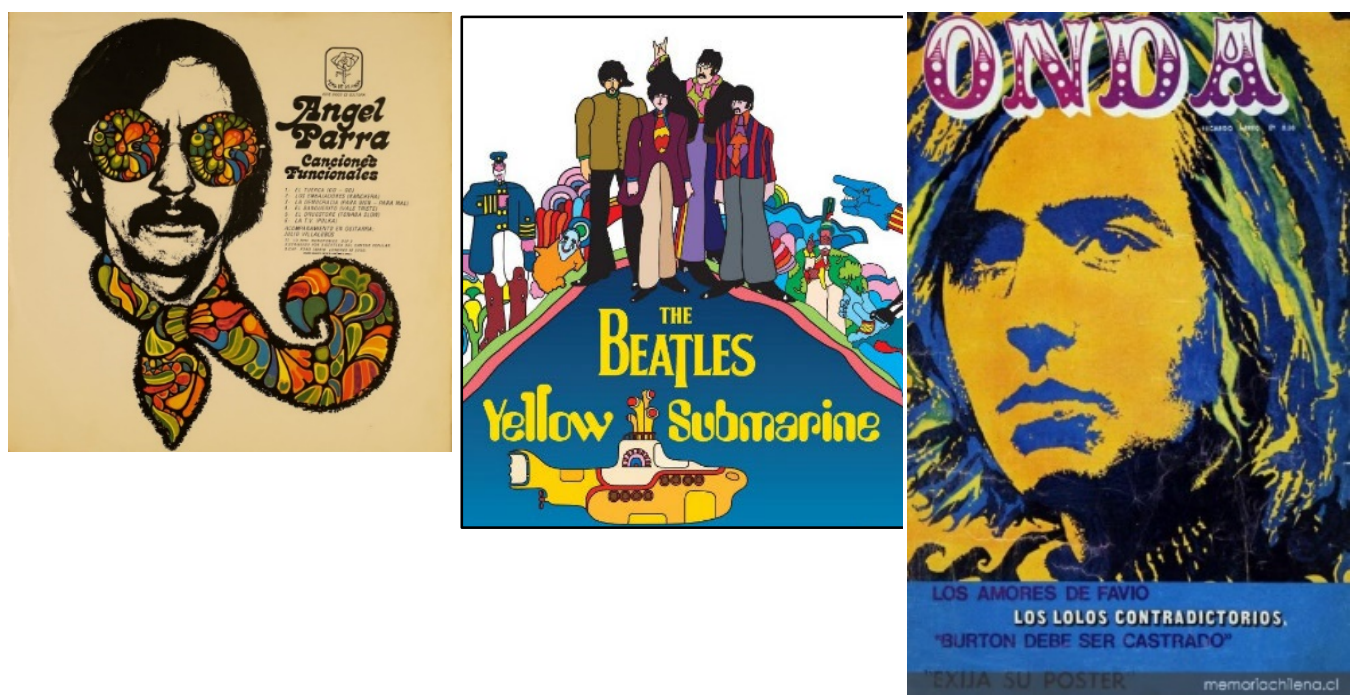

A la izquierda, portada del disco Canciones Funcionales, Ángel Parra (1969). Al medio, portada de disco Yellow Submarine, The Beatles (1969). A la derecha, portada de la revista Onda, 1971 (Fuente: www.memoriachilena.cl)

\section{SOBRE SEXO Y DROGAS}

A pesar de que los jóvenes de izquierda dedicaron su tiempo a tareas políticas y sociales, principalmente los trabajos voluntarios o las manifestaciones callejeras, nunca abandonaron sus espacios de distención y de diversión, como las kermeses y las peñas. Muchas de estas actividades incluso se entrelazaron con el quehacer político, ya que tuvieron el objetivo de recaudar fondos para diferentes propósitos, como el centro de alumnos, trabajo en las poblaciones o alguna iniciativa solidaria para familias o vecinos:

Entonces, se empiezan a armar todas esas actividades, y las actividades de día sábado eran... eso po', no faltaba el típico que empieza la onda del Quilapayún, Intilllimani, toda esa onda, y los grupos que cantaban y las cosa es juntarse en una casa, y se armaba, además dentro de los trabajo pa' juntar plata, las peñas, todas esas cosas. (Araya, entrevista, 2016)

En el caso de los jóvenes estudiantes, hay que recordar que una de las tareas de los centros de alumnos fue generar espacios para la recreación y 
fiestas escolares, así, estos fueron adquiriendo experiencia organizativa y entremezclando la cultura de izquierda con la entretención y la diversión. Una diversión «más comprometida». Por este motivo, y a través de las fuentes revisadas, es posible comprender que la responsabilidad de coordinación del centro de alumnos no solo tuvo que ver con las marchas o tomas de los colegios $^{15}$, sino también con ser capaces de dialogar y compartir con todo el estudiantado a través de estas instancias. De esta manera, las redes en torno al colegio y los trabajos en población fueron los escenarios principales de estas fiestas de lolos y lolas, tal como se extrae del siguiente testimonio: «Éramos tres bases en el Manuel de Salas y todo el sector constituíamos el comité local, que reuníamos todo el sector Ñuñoa-Providencia. Entonces, ahí nos mezclábamos todos, éramos amigos, hacíamos fiestas (...) y bailábamos mucho» (Ortiz, entrevista, 2016). Los círculos políticos fueron parte importante de los espacios de diversión. Las caras se repetían, y los amigos del baile y el malón, muchas veces eran los mismos compañeros que estaban al lado en las protestas y manifestaciones.

En este contexto, cabe preguntarnos si el consumo de marihuana en la época constituyó un elemento importante para los jóvenes de izquierda y qué posturas tomaron al respecto, considerando que se encontraban imbuidos por una propaganda y ambiente donde el hipismo era el protagonista, y asociado a esta cultura se vinculaban diferentes acciones, donde la marihuana aparece como una temática recurrente en los diferentes medios escritos y orales consultados, siendo fundamental su problematización.

El consumo de la marihuana fue visto como una amenaza en algunos sectores de la sociedad, que la consideraron un verdadero peligro entre los jóvenes. Como muestran las autoras Richard, Viveros y Ortiz (1972), el 17 de abril de 1971, El Mercurio titulaba en una de sus páginas: «Lucha contra el uso de drogas. La marihuana, comienzo de la degradación» (p. 30). De acuerdo con su estudio «¿Fuma marihuana el estudiante chileno?», un 35\% de estudiantes reconocía su consumo.

${ }^{15}$ Las tomas y retomas de los colegios se dio fundamentalmente en el contexto de defensa de la Escuela Nacional Unificada. Ver en: Jorge Rojas Flores, «Los estudiantes secundarios durante la Unidad Popular, 1970-1973», revista Historia, ${ }^{\circ}$ 42, vol. II, julio-diciembre, 2009. 
Esta situación refleja una realidad latente, que concuerda con los testimonios de algunos de los entrevistados, quienes declaran haber consumido marihuana:

(...) no existía la droga como existe la cosa hoy, el LSD, la pasta. Nosotros fumábamos marihuana [...] calcula que hacíamos un Led Zeppelin que le llamábamos, que era que juntabai toda la marihuana que tenías, le ponías coñac, alguna cosa, la prendías, nos tapábamos con una frazada y ahí fumábamos... era rasca la marihuana que fumábamos, no era gran cosa. (Silva, entrevista, 2016).

Si bien la marihuana fue parte de la vida de los jóvenes, no parece haber sido un elemento primordial o determinante al momento de hablar de su consumo, «no era gran cosa». No se encontraba en uno de los ejes constitutivos de la cotidianeidad juvenil, por esto se hace necesario mirar con precaución los índices presentados anteriormente, considerando que la sustancia más masificada entre los jóvenes de la época no era la marihuana, sino más bien, el cigarrillo. Probablemente debido a la concepción de inocuidad de esta sustancia, observable en el siguiente cuadro:

CUAdRo 1. PERCEPCIÓN COMPARATIVA DE GRADO DE PELIGROSIDAD DE TABACO, ALCOHOL, MARIHUANA Y LSD ${ }^{16}$

\begin{tabular}{|l|l|l|l|l|l|}
\hline \multicolumn{2}{|c|}{ Escala de peligrosidad } & Tabaco & Alcohol & Marihuana & \multicolumn{1}{c|}{ LSD } \\
\hline \multirow{4}{*}{ Ningún peligro } & & $\%$ & $\%$ & $\%$ & $\%$ \\
\cline { 2 - 7 } & 1 & 11,2 & 3,4 & 4,5 & 1,0 \\
\cline { 2 - 7 } & 2 & 16,5 & 5,8 & 5,4 & 1,0 \\
\cline { 2 - 6 } & 3 & 17,5 & 9,4 & 6,3 & 1,0 \\
\cline { 2 - 6 } & 4 & 20,7 & 14,0 & 10,5 & 2,5 \\
\cline { 2 - 6 } & 5 & 20,1 & 19,6 & 18,9 & 5,3 \\
\cline { 2 - 6 } & 6 & 9,4 & 23,6 & 28,4 & 14,6 \\
\hline Extremadamente peligroso & 7 & 3,5 & 22,6 & 24,9 & 70,9 \\
\hline No contesta & & 1,1 & 1,6 & 1,0 & 3,6 \\
\hline
\end{tabular}

16 Extraído de Patricia Richard, Ana María Viveros y Liana Ortiz (1972). ¿Fuma marihuana el estudiante chileno? Santiago de Chile: Nueva Universidad, p. 71. 
Sin duda, el consumo de marihuana ya comenzaba a establecerse como un tema en la sociedad, siendo apoyado y rechazado por igual. Un ejemplo de esto se encuentra en un reportaje de la revista Ramona que, en el año 1973, presentó la noticia sobre la posibilidad de que el consumo de marihuana fuera legal en Holanda. A partir de este acontecimiento, se problematiza respecto a los efectos de la droga, utilizando una serie de testimonios. Uno de estos corresponde a un joven de 18 años, aproximadamente, que opina: «iLa raya! Eso deberían haberlo hecho hace mucho tiempo. Es que nosotros somos tan subdesarrollados» (Ramona, 1973: 26). Posteriormente se entrevista a Mariana Candia, de 16 años, estudiante: «No, no estoy de acuerdo. Si la marihuana se vendiera como los cigarrillos, el vicio en los cabros sería mucho más grande. ¿Te imaginai? Quedaría la tremenda escoba» (Ramona, 1973: 27). Las opiniones diversas manifestaban las tensiones en torno a problemáticas más «cotidianas» que abarcaba la revista Ramona, abriendo el debate en torno a su consumo entre los jóvenes chilenos. Para la izquierda más ortodoxa, el consumo de drogas se relacionaba con una juventud enajenada, de clase alta, vinculada al hipismo, que lo único que buscaba era la participación en carreras de autos, seguir la moda gringa y ser «hijitos de sus papis». Para reforzar esta idea, el gobierno ocupó sus canales mediáticos, en este caso lo vemos en la revista Onda, en la sección «Así soy yo», encontramos el relato de un joven de 16 años en torno al consumo de lo que él denomina la «yerba», quien finaliza su historia ya recuperado del consumo, diciendo: "Le haría un llamado a la juventud, que se preocupe más por su país» (p. 45).

De igual manera, en Descomedidos y Chascones (Flores, 1973), cuando a los jóvenes de izquierda se les muestran imágenes de un encuentro de música hippie donde se ven cuerpos danzando sin sentido y «volaos», un joven reacciona diciendo: «Me ha impresionado la película que acabo de ver, porque no puede ser, no puede ser que aquí en Chile en este instante, existan ese tipo de jóvenes [...] yo creo que los que mejor representan la juventud chilena son los mineros del carbón [...]». Rechazo, aprobación, enajenación o diversión, son algunos de los conceptos que envuelven un tema que ocupó múltiples páginas y secciones de las diferentes fuentes consultadas. Es que, si bien el deber ser del joven revolucionario estaba fuera del consumo de las drogas, estos no dejaron de experimentar con sus efectos. Tal como lo menciona Arnaldo Guevara (Entrevista, 2016): «Escuchábamos música rock, Mick Jagger, fumando marihuana, súper tranquilos, yo no era muy bueno para fumar, pero el ambiente era marihuanero». Por lo tanto, a pesar de ser militante de las 
Juventudes Comunistas, el consumo de marihuana y la música en inglés no estuvieron vedados de su experiencia ${ }^{17}$.

Otro elemento rupturista con la identidad militante clásica importante de analizar tiene que ver con las relaciones amorosas y sexuales de los y las jóvenes. La década de los sesenta atravesó por un vertiginoso proceso de apertura sexual, que en Chile estuvo acompañado del influjo del movimiento hippie y la «revolución sexual» en Europa. Los jóvenes del periodo manifestaron una curiosa inquietud por su sexualidad, en un contexto donde la apertura a la experimentación del sexo libre del movimiento hippie, las apasionadas ideas y estéticas europeas, y la difusión de los métodos anticonceptivos alimentaban cada vez más sus preguntas. El apoyo gubernamental recibido durante la presidencia de Frei Montalva a la distribución de:

(...) anticonceptivos transformaron al control de la natalidad en materia de discusión pública en la segunda mitad de los años sesenta, (además) el financiamiento norteamericano de muchas de las iniciativas de planificación familiar en los países subdesarrollados hizo de este asunto un tópico especialmente peliagudo para la izquierda chilena. (Salgado, 2014: 158)

En torno a dicha temática, la revista Ramona fue uno de los medios escritos más interesantes en el tratamiento de la relación entre juventud y sexualidad. A través de diversas historias, reportajes y noticias, dio cuenta de algunas de las tensiones vividas en ese momento, y que llevaron a los jóvenes de izquierda a enfrentarse a «los más viejos». Particularmente conflictivo fue el tratamiento de las relaciones prematrimoniales, que suscitó una gran discusión a nivel intergeneracional, al igual que la publicación de imágenes de desnudos en las páginas de Ramona (Salgado, 2014).

La virginidad fue un asunto sumamente importante y tratado con bastante seriedad. Por ejemplo, en una discusión entre jóvenes, podemos extraer la siguiente cita: «No hablemos más de quitar la virginidad, compañeros. Hablemos más bien de liberar la virginidad. Hay que dejar atrás una serie de prejuicios puritanos» (Ramona, 1972: 16). El diálogo se desplegó a través de

17 Podemos concluir que el interés mayor del gobierno fue frenar el consumo de alcohol. Ver en: Héctor Ríos, Entre ponerle y no ponerle (1971). 
dos páginas de la revista, lo que nos habla de su complejidad como temática y de las tensiones presentes en la juventud en torno a las vivencias sexuales, de pareja y matrimonio, que pusieron en jaque al statu quo, sustentado en una concepción conservadora de la sexualidad que establecía que el sexo debía ser solo para cuando uno está casada/o, y responsabilizaba a la mujer a «cuidar»y «mantener»su virginidad. Para el autor Alfonso Salgado (2014), la revista Ramona fue un soporte importante donde se manifestó el quiebre generacional experimentado a partir de los sesenta, gestándose cambios culturales revolucionarios que dejaban relucir una mayor apertura en torno al sexo y su ejercicio. Muchos de estos desencuentros se centraron en las posibilidades de apertura sexual otorgadas por los métodos anticonceptivos, aunque existieron igualmente puntos en los que coincidía la generalidad de la izquierda, como fue el rol central de la familia tradicional en la estructura social. Reacios a experimentos hippies como las alternativas comunitarias, o las opciones individualistas, que consideraron como «escapismo». Según Salgado (2014), desde Ramona proclamaron que «en las condiciones actuales, parece no existir mejor sistema de vida que el de vivir juntos un hombre y una mujer, teniendo hijos, siendo amigos, y tratando de que sea relación sea tan movida como cada uno es individualmente» (p. 164).

Por otra parte, es importante poner en su debido contexto a la revista Ramona, medio escrito que no tuvo la misma circulación que Ritmo, pero que hoy constituye el testimonio de las Juventudes Comunistas de la época. En este sentido, es posible observar un declarado interés en el tratamiento y concepción de la sexualidad en todos sus ámbitos: reproducción, roles de género, sexo, virginidad, etc. Por ejemplo, en pleno contexto de polarización política, en el mes de abril de 1972, la revista publicó al menos cuatro reportajes en torno a los diferentes métodos anticonceptivos, sus usos, los mitos alrededor de estos y los efectos que generaban ${ }^{18}$. Un importante interés por «acompañar» la revolución social y política, a partir de los modos de ejercer la sexualidad juvenil, María Luisa Ortiz (Entrevista, 2016) recuerda:

Depende de la cultura que vengas [...] en el ambiente que yo me movía, mis amistades, yo diría que no era tema restringido, o sea, mis amigas se

${ }^{18}$ El 3 de abril, un reportaje-entrevista sobre a píldora anticonceptiva. El 10 de abril, otro sobre los dispositivos intrauterino. El 17 de abril, uno acerca de los métodos tradicionales de anticoncepción y el 24 de abril, un reportaje sobre métodos anticonceptivos para hombres. 
acostaban con sus pololos en enseñanza media, no era tema censurado ni nada de eso. Ahora, tampoco era que los papás lo aceptaban, ni nada de eso, era todo escondido, pero nadie se lo cuestionaba. No había condones, ni miedo al sida, ni ninguna de esas cuestiones, las pastillas no más.

En la primera línea de la cita, podemos encontrar la clave de la problemática sobre el tema en cuestión: «Depende de qué cultura vengas». Este enfoque no se encontraba precisamente acorde con la visión política de su círculo social. En este sentido, y al igual que con la marihuana, los jóvenes fueron experimentando diferentes maneras de entender el sexo, pero dentro de una cultura adultocéntrica que puso en valor el sexo dentro del matrimonio.

Desde otra mirada, más que nada educativa, la revista Onda tiene en cada uno de sus números una sección denominada «Información sexual», que se encontraba a cargo de la Universidad de Chile, Facultad de Filosofía y Educación, Unidad de Sexología, la que más que mostrar debates y visiones entre los jóvenes, mostraba diversas noticias relativas a una educación sexual, donde algunos de sus tópicos fueron «Poluciones nocturnas» (Onda, 1971: s/n) o «La menstruación» (Onda, 1971: 40). En este sentido, la revista cumple su objetivo primordial: ser un ente canalizador de debates y premisas del gobierno de la Unidad Popular, es por esta razón que el ámbito sexual se limita más bien a un tema unidireccional guiado por un ente facultativo en la materia.

\section{Conclusiones}

A partir de la bibliografía estudiada y fuentes analizadas en este artículo, mencionamos que existió, durante el periodo de la Unidad Popular, una intención por promover, desde la revista Ritmo y el programa de televisión Música Libre, un modelo de juventud que, inspirado en la mercantilización cultural norteamericana, los mostraba como jóvenes alegres e individualistas. Sin embargo, frente a la emergencia de las y los jóvenes en la arena política, donde desempeñaron un rol destacado en la promoción de nuevos temas y enfoques, participando a su modo de la «revolución a la chilena», se intentó encauzar este impulso por caminos más inocuos, erigiendo un prototipo despreocupado, cuyas energías debían centrarse en la jovialidad, los bailes, la música y otros intereses, considerados como propios de su edad. Por otro lado, desde los discursos adultocéntricos de izquierda, los hicieron creer que estos 
canales llevarían a la despolitización y nihilismo social. Sin embargo, y a partir de los ejes analíticos propuestos, el despertar joven comenzó un vertiginoso desarrollo de un movimiento cultural democratizador y comprometido con los procesos revolucionarios de nuestro país, pero que no rechazó ninguna de las alternativas identitarias presentes en la época. Los y las jóvenes de izquierda fueron decidiéndose por una cultura juvenil comprometida con sus ideales políticos, pero permeando otros espacios e identidades, el hipismo, la música en inglés, entre otros. El proceso revolucionario «a la chilena» se caracterizó por una serie de elementos que fueron permeando, dialogando y cambiando en los sujetos las percepciones y concepciones de sociedad.

Ahora bien, rompiendo la comprensión dual de la cultura juvenil, o más bien de la cultura de izquierda o de derecha, los jóvenes analizados en este artículo, a partir de los ejes anteriormente mencionados, experimentaron diferentes vivencias y alternativas culturales, entraron a distintos mundos sin abandonar los propósitos sociales y políticos arraigados en el anhelo de la construcción de una nueva sociedad. En este sentido, la diversidad, la diferencia y la riqueza cultural de la época fueron recibidas con el entusiasmo y la curiosidad propias de la juventud, que, no sin resistencia y cuestionamiento de sus mayores, de los partidos guiados desde una visión adultocentrista, lograron impactar un mundo ya en transformación, fuera a través de sus cuestionamientos como de sus acciones de respaldo a un proyecto que creían beneficioso para todas y todos. Elementos que se observan al mostrar el consumo musical tanto de la $\mathrm{NCCH}$ como los grupos «yanquis», o ver programas de televisión relacionados con una idea conservadora de la juventud y vivir en una tensión con estos mismos cánones.

Así, los jóvenes experimentaron elementos de continuidad y ruptura constantemente tensionados por el «deber ser» social y militante, principalmente en torno a la sexualidad y el uso de la marihuana, que, empero, no pudo ni quiso restarse de las llamativas alternativas consideradas perniciosas para su edad, permitiéndoles crear una identidad propia, con muchas influencias, pero guiada por las decisiones realizadas sobre la base de su experiencia.

En este sentido, este trabajo colabora en entender las culturas de las izquierdas de la época no solo desde los discursos oficiales o en contraposición a estos, es decir, cultura hegemónica o contrahegemónica (Barr-Melej, 2017), sino más bien de complejizar las experiencias y, por lo tanto, las prácticas e imaginarios culturales durante la Unidad Popular, los que, a su vez, también 
dan cuenta de un ejercicio político juvenil ligado al interés por la lucha e igualdad social. Entender la experiencia juvenil desde el interior de los sujetos y sus vivencias y no aferrarnos a las concepciones binarias de cultura y contracultura, sino más bien de la existencia de circulación, de manera redundante, una experiencia cultural. Por otra parte, es necesario mencionar que este trabajo corresponde a un análisis de algunos de varios ejes políticoculturales, por lo tanto, deja abiertas líneas investigativas que puedan profundizarse a posteriori, sobre todo en elementos relacionados con los ámbitos de la vida privada y de otras maneras de desarrollar la cultura juvenil en un contexto de emergencia de dichos sujetos a nivel mundial.

RECIBIDO: 20 DE ABRIL DE 2020

ACEPTADO: 4 DE JUNIO DE 2020

\section{BIBLIOGRAFÍA}

\section{Libros}

Barr-MeleJ, P. (2017). Psychedelic Chile. Youth, Counterculture, and politics on the Road to Socialism and Dictatorship. North Carolina: The University of North Carolina Press.

CARrasco, E. (2004). El sueño pintado. Milán: Hobby\&Work.

CURY, M. (2018). El protagonismo popular chileno. experiencias de clase y movimientos sociales en la construcción del socialismo (1964-1973). Santiago de Chile: LOM Ediciones.

Castillo EspinOzA, E. (2004). El cartel chileno 1963-1973. Santiago de Chile: Ediciones B.

GARCÍA, M. (2013). Canción valiente. 1960-1989. Tres décadas de canto social y politico en Chile. Santiago de Chile: Ediciones B.

Manzano, V. (2017). La era de la juventud en Argentina. Cultura, política y sexualidad desde Perón hasta Videla. Bogotá: Fondo de Cultura Económica. 
McSherry, J. P. (2017). La Nueva Canción Chilena. El poder político de la música, 1960-1973. Santiago de Chile: LOM Ediciones.

LAMADRID, S. (2014). Ritmo revisitado. Representaciones de género en los 60. Santiago de Chile: Cuarto Propio.

Richard, P., Viveros, A. M. y Ortiz, L. (1972). ¿Fuma marihuana el estudiante chileno? Santiago de Chile: Nueva Universidad.

SAlas, F. (2003). La primavera terrestre. Cartografias del rock chileno y la Nueva Canción Chilena. Santiago de Chile: Cuarto Propio.

Thompson, E. P. (1981). Miseria de la teoría. Barcelona: Crítica.

WinN, P. (2013). La revolución chilena. Santiago de Chile: LOM Ediciones. . (2004). Tejedores de la Revolución. Los trabajadores de Yarur y la vía chilena al socialismo. Santiago de Chile: LOM Ediciones.

Zolov, E. (2002). Rebeldes con causa: la contracultura mexicana y la crisis del Estado patriarcal. México, D. F.: Grupo Editorial Norma.

\section{Artículos}

Álvarez, R. (2014). Trabajos voluntarios: el hombre nuevo y la creación de una nueva cultura en el Chile de la Unidad Popular. En J. PINTO, Fiesta y Drama. Nuevas historias de la Unidad Popular (pp. 173-204). Santiago de Chile: LOM Ediciones.

BARR-MELEJ, P. (2009). Hippismo a la chilena: Juventud y heterodoxia cultural en un contexto transnacional (1970-1973). En F. P. RIQUELME, Ampliando miradas: Chile y su historia en un tiempo global (pp. 305325). Santiago de Chile: RIL Editores-Instituto de Historia UC.

Flores, J. R. (2009). Los estudiantes secundarios durante la Unidad Popular, 1970-1973. Historia, II(2), 471-503.

Gaudichaud, F. (2013). A 40 años del golpe. Historiografía crítica y pistas de investigación para (re)pensar la Unidad Popular. Tiempo Histórico, 6, 63-79.

GoICOVIC, I. (2000). Del control social a la política social. La conflictiva relación entre los jóvenes populares y el Estado en la historia de Chile. Última Década, 8(12), 103-123.

Moraga VAlLE, F. (2006). «Ser joven y no ser revolucionario». La juventud y el movimiento estudiantil durante la Unidad Popular. En F. ZAPATA, Frágiles suturas. Chile a treinta años del gobierno de Salvador Allende (pp. 365-411). México, D. F.: El Colegio de México. 
SALGADO, A. (2014). «Una pequeña revolución». Las juventudes comunistas ante el sexo y el matrimonio durante la Unidad Popular. En R. ÁlVAREZ y M. Loyola (Comps.), Un trébol de cuatro hojas. Las juventudes comunistas en Chile en el siglo $X X$ (pp. 144-169). Santiago de Chile: Ariadna.

SANTA CRUZ, Y. (2019). Las y los pingüinos en la Unidad Popular. La vida política de los estudiantes secundarios de izquierda en Santiago. En G. D. GERMinal, Se levanta el clamor popular. Experiencias del pueblo organizado durante el gobierno de los mil dias 1970-1973 (pp. 159194). Concepción: Sartaña.

\section{Tesis}

GRANDÓn LEAL, R. A. (2010). Brigadas Ramona Parra: muralismo político y debate cultural en la Unidad Popular. (Tesis para optar al grado de licenciada en Historia). Universidad Alberto Hurtado, Santiago, Chile.

\section{Fuentes primarias}

ABARCA, L. y ForCh, J. (1972). Viaje por la juventud. Santiago de Chile: Quimantú.

\section{Discos}

Led ZePPELIN (1971). «Stairway to Heaven». Disco Led Zeppelin IV, Atlantic.

INTI IllimANI (1970). «Canción del poder popular». Álbum Canto al programa, DICAP.

QUILAPAYÚN (1969). «A la mina no voy». Álbum Basta, DICAP.

VÍCTOR JARA (1971). «A Cuba». Álbum El derecho de vivir en paz, DICAP.

\section{Documentales}

CARlos Flores del PINO (1973). Descomedidos y chascones.

HÉCTOR RÍOs (1971). Entre ponerle y no ponerle. Universidad de Chile.

\section{Revistas}

Onda

- $\quad 1$ de octubre de 1971.

- $\quad 15$ de octubre de 1971. 
- $\quad 17$ de septiembre de 1971.

- $\quad 3$ de marzo de 1972.

Ramona

- $\quad 1$ de octubre de 1971.

- $\quad 3$ de abril de 1972.

- $\quad 10$ de abril de 1972.

- $\quad 17$ de abril de 1972.

- $\quad 24$ de abril de 1972.

- $\quad 30$ de mayo de 1972.

- $\quad 6$ de marzo de 1973.

\section{Entrevistas}

- $\quad$ Arnaldo Guevara (2016). Santiago, 10 de junio. Realizada por Yanny Santa Cruz.

- $\quad$ Lelia Pérez (2006). Testimonio N’2. Archivo Oral Villa Grimaldi.

- $\quad$ María Eugenia Letelier (2015). Santiago, 4 de noviembre. Realizada por Yanny Santa Cruz.

- $\quad$ María Luisa Ortiz (2016). Santiago, 2 de febrero. Realizada por Yanny Santa Cruz.

- $\quad$ Sergio Silva (2016). Santiago, 8 de marzo. Realizada por Yanny Santa Cruz.

- Vilma Araya (2016). Santiago, 5 de marzo. Realizada por Yanny Santa Cruz. 